\title{
La cerámica estilo Carambolo y su contexto cultural en la transición del Bronce Final a la Primera Edad del Hierro
}

\section{The Carambolo style and its cultural context during the transition from the Late Bronze Age to the Iron Age}

\author{
PEDRo Miguel NaRANJo \\ Universidad de Castilla-La Mancha \\ Avenida de Camilo José Cela, S/N \\ Campus Universitario, 13071 Ciudad Real \\ Pedro_N9o@hotmail.com \\ https://orcid.org/0000-0003-4356-4511
}

\begin{abstract}
Resumen
En este artículo se ofrece una visión general y actualizada sobre los diferentes aspectos de la cerámica estilo Carambolo, como las formas, decoración, cronología, filiación cultural, etc. Este trabajo de conjunto se complementa con los resultados de dos analíticas inéditas por DRX efectuadas sobre dos fragmentos del Cerro Macareno (La Rinconada, Sevilla), piezas que hasta ahora solo se conocían por referencias textuales. Los resultados verifican la existencia de, al menos, dos centros de producción para esta cerámica típica del suroeste que cronológicamente se ubica en la transición del Bronce Final a la Primera Edad del Hierro. Su decoración, en consonancia con el Geométrico griego, se desarrolló sobre formas locales típicas del Bronce Final, tratándose de una producción híbrida en la que se conjugaron varias tradiciones. Se trata, pues, de un fiel testimonio del contexto cultural de este periodo en el que las poblaciones locales del suroeste entraron en contacto con otras culturas mediterráneas.
\end{abstract}

Palabras clave: cerámica, Carambolo, suroeste, Bronce Final, Hierro I

\section{Abstract}

In this paper, I present an overview of the different aspects of Carambolo ware such as shapes, chronology, decoration, cultural interpretation and so on. Besides, I present the results of mineralogical analysis in two fragments of Cerro Macareno (La Rinconada, Sevilla). We know only the textual references about these fragments. The results confirm the existence of a lot of centers to make this ceramic during the transitional period between the Late Bronze Age and the Iron Age. Its decoration, according to geometric Greek pottery, was developed on typical shapes of the Late Bronze Age. So, we can consider this pottery like a hybrid production. The Carambolo ware is an example of the cultural context during this period in the southwest, where the local people contacted with other Mediterranean cultures.

Key words: pottery, Carambolo, southwest, Late Bronze, Iron Age 


\section{Introducción: denominación, estado de la cuestión y distribución}

Esta producción, denominada tipo Carambolo por Carriazo (1969:315; 1973: 504) a partir de sus excavaciones en el yacimiento homónimo de Camas (Sevilla), fue considerada desde su descubrimiento como el fósil guía más elocuente de la cultura tartésica en su etapa de formación (Carriazo, 1973: 472-477). No obstante, este tipo cerámico ya fue documentado por Esteve Guerrero (I945: 39, fig. 6., lám. X) entre 1942 y 1943 en el yacimiento de Mesas de Asta (Jerez de la Frontera, Cádiz), aunque fue erróneamente adscrito al Bronce Mediterráneo I. Posteriormente, por su dispersión en la Baja Andalucía, se denominó Guadalquivir I (Ruiz Mata, I984-1985).

Durante los años sesenta y setenta del siglo xx, y a raíz de las interpretaciones de Carriazo, se produjo una estrecha vinculación entre esta cerámica y la cultura tartésica (Abad, 1979; Bendala, I979; Fernández Miranda, I979; Fernández Jurado, I988-ı989; Ruiz Mata, I984-1985), considerándose anterior a la colonización fenicia que en aquel momento se fijaba en torno al 750 a. C. (Almagro-Gorbea, 1977: 496). A mediados de la década de los años noventa esta propuesta cronológica fue cuestionada por Amores (1995) ante la existencia de cerámica a torno en el «fondo de Cabaña» del Carambolo Alto, aunque no fue hasta los inicios del siglo XXI, a partir de los resultados obtenidos en las posteriores excavaciones efectuadas en El Carambolo (Fernández Flores y Rodríguez Azogue, 2007) y la reciente publicación monográfica sobre la cerámica estilo Carambolo exhumada en el mismo (Casado, 2015), cuando verdaderamente cambiaron las propuestas de interpretación sobre Tarteso en general y esta producción en particular. No obstante, ya Belén y Escacena (1997) habían apuntado algunas vías alternativas a partir de su interpretación del enclave como un centro de culto fenicio. Estas nuevas interpretaciones relacionan la cerámica en cuestión con la cultura fenicia en un marco cronológico de la Primera Edad del Hierro, provocando la reacción de algunos investigadores que ubican la cerámica estilo Carambolo del yacimiento homónimo en una fosa del Bronce Final previa a la fundación del primer santuario (Carambolo V), integrada por los niveles inferiores diferenciados por Carriazo en su «fondo de cabaña» (Torres, 20r6). Las propuestas postcoloniales, por su parte, entienden El Carambolo como un espacio en el que confluyeron poblaciones locales y foráneas de diverso origen (Delgado, 2010), dando lugar a los fenómenos de hibridación que fosilizan esta producción.

Las últimas investigaciones sobre estas cerámicas pintadas desaconsejan el uso del término «tipo», ya que se considera un concepto constreñido a una tipología concreta que no se ajusta a la realidad de estas producciones desarrolladas sobre la tradición vascular de varias comunidades (Torres, 2019: 242). En su lugar, se ha propuesto el término «estilo», mucho más flexible y relacionado con la decoración, por lo que en este trabajo se denominará estilo Carambolo. Igualmente inadecuado resulta el término Guadalquivir I, ya que los ejemplares de Mértola (Beja, Portugal) (Barros, 20I2: fig. 6), Alarcos (Poblete, Ciudad Real) (García Huerta y Fernández Rodríguez, 2000: fig. 5:2) y Útica (Túnez) (com. pers. M. Torres) contradicen la connotación geográfica del mismo, si bien la dispersión de esta cerámica se centra en el Bajo Guadalquivir (figura I).

La concentración en la zona más noroccidental de la actual provincia de Cádiz, la parte más oriental de la provincia de Huelva, el centro de la provincia de Sevilla y el sur de la provincia de Córdoba indicaría la existencia de unas comunidades inmersas en unos mismos gustos decorativos, un espacio geográfico que coincide con la zona nuclear de la cultura tartésica (Celestino y López-Ruiz, 2020: mapa 7). Estos territorios contarían con el Guadalquivir como una de las principales vías de comunicación, de ahí que los hallazgos se localicen en torno al río. Los ejemplares situados fuera de esta zona, como el de Alarcos, se explicarían por las relaciones culturales entre el Alto Guadiana y el Bajo Guadalquivir en un periodo de transición del Bronce Final a la Primera Edad del Hierro, mientras que el fragmento de Útica, al igual que otras cerámicas locales del suroeste como una cazuela bruñida de carena alta localizada en este mismo yacimiento (López Castro et alii, 20I6: fig. Iо:I), se explicaría por las relaciones comerciales entre las poblaciones locales del suroeste y los fenicios en esta época, unas relaciones en las que los fenicios adquirieron algunos bienes de origen peninsular. 


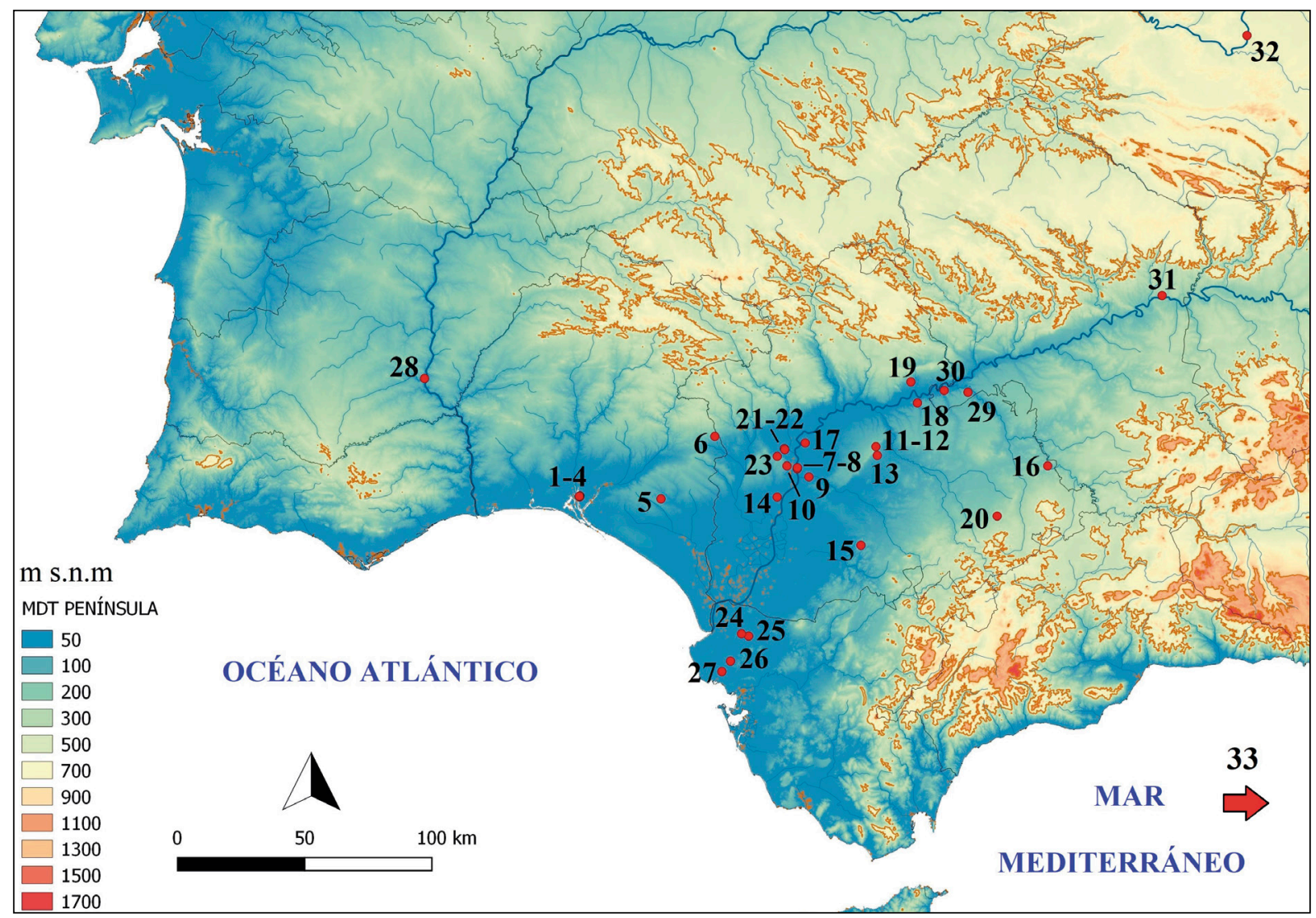

Figura 1. Mapa de la península ibérica con la dispersión de la cerámica estilo Carambolo: 1. Cabezo de San Pedro (ciudad de Huelva, Huelva); 2. Calle Concepción, 3 (ciudad de Huelva, Huelva); 3. Calle Méndez Núñez, 7-13/Plaza de las Monjas, 12 (ciudad de Huelva, Huelva); 4. Calle Puerto, 6 (ciudad de Huelva, Huelva); 5. San Bartolomé (Almonte, Huelva); 6. Peñalosa (Escacena del Campo, Huelva); 7. Real Alcázar de Sevilla (ciudad de Sevilla, Sevilla); 8. Calle Abades, 41-43 (ciudad de Sevilla, Sevilla); 9. Universidad Laboral (Alcalá de Guadaira, Sevilla); 10. El Carambolo (Camas, Sevilla); 11. CA-80/B (Carmona, Sevilla); 12. Solar $\mathrm{n}^{\circ} 20$ de la calle Diego Navarro (Carmona, Sevilla); 13. El Picacho (Carmona, Sevilla); 14. Cerro de San Juan (Coria del Río, Sevilla); 15. Cerro del Casar (EI Coronil, Sevilla); 16. Alhonoz (Herrera, Sevilla); 17. Cerro Macareno (La Rinconada, Sevilla); 18. Cortijo del Acebuchal (Lora del Río, Sevilla); 19. Mesa de Setefilla (Lora del Río, Sevilla); 20. Cuesta de los Cipreses (Osuna, Sevilla); 21. Jardín de Alá (Salteras, Sevilla); 22. Cerro de la Cabeza (Santiponce, Sevilla); 23. Cerro de la Cabeza (Valencina de la Concepción, Sevilla); 24. Cerro de la Compañía (Jerez de la Frontera, Cádiz); 25. Mesas de Asta (Jerez de la Frontera, Cádiz); 26. Pocito Chico (Puerto de Santa María, Cádiz); 27. Campillo (Puerto de Santa María, Cádiz); 28. Mértola (Beja, Baixo Alentejo); 29. Vega de Santa Lucía (Palma del Río, Córdoba); 30. La Saetilla (Palma del Río, Córdoba); 31. El Llanete de los Moros (Montoro, Córdoba); 32. Alarcos (Poblete, Ciudad Real); 33. Útica (Túnez). A partir de Torres, 2002: VII.4, modificado y actualizado

Figure 1. Map of the Iberian Peninsula with the dispersion of the Carambolo style: 1. Cabezo de San Pedro (city of Huelva, Huelva); 2. Concepción street, $3^{\text {rd }}$ (city of Huelva, Huelva); 3 . Méndez Núñez street, 7-13 ${ }^{\text {th }} /$ Plaza de las Monjas, $12^{\text {th }}$ (city of Huelva, Huelva); 4. Puerto street, $6^{\text {th }}$ (city of Huelva, Huelva); 5. San Bartolomé (Almonte, Huelva); 6. Peñalosa (Escacena del Campo, Huelva); 7. Real Alcázar de Sevilla (city of Sevilla, Sevilla); 8. Abades street, 41-43 $3^{\text {th }}$ (city of Sevilla, Sevilla); 9. Universidad Laboral (Alcalá de Guadaira, Sevilla); 10. El Carambolo (Camas, Sevilla); 11. CA-80/B (Carmona, Sevilla); 12. place no. 20 of the Diego Navarro street (Carmona, Sevilla); 13. El Picacho (Carmona, Sevilla); 14. Cerro de San Juan (Coria del Río, Sevilla); 15. Cerro del Casar (El Coronil, Sevilla); 16. Alhonoz (Herrera, Sevilla); 17. Cerro Macareno (La Rinconada, Sevilla); 18. Cortijo del Acebuchal (Lora del Río, Sevilla); 19. Mesa de Setefilla (Lora del Río, Sevilla); 20. Cuesta de los Cipreses (Osuna, Sevilla); 21. Jardín de Alá (Salteras, Sevilla); 22. Cerro de la Cabeza (Santiponce, Sevilla); 23. Cerro de la Cabeza (Valencina de la Concepción, Sevilla); 24. Cerro de la Compañía (Jerez de la Frontera, Cádiz); 25. Mesas de Asta (Jerez de la Frontera, Cádiz); 26. Pocito Chico (Puerto de Santa María, Cádiz); 27. Campillo (Puerto de Santa María, Cádiz); 28. Mértola (Beja, Baixo Alentejo); 29. Vega de Santa Lucía (Palma del Río, Córdoba); 30. La Saetilla (Palma del Río, Córdoba); 31. El Llanete de los Moros (Montoro, Córdoba); 32. Alarcos (Poblete, Ciudad Real); 33. Útica (Túnez). From Torres, 2002: VIl.4, modified and updated

Con esta información, y a raíz de los nuevos hallazgos, se ha marcado como objetivo la actualización de los datos sobre la cerámica estilo Carambolo. Descubrimientos onubenses tan destacados, como los depósitos de Méndez Núñez 7-r3/Plaza de las
Monjas I2 (González de Canales et alii, 2004) y Concepción 3 (González de Canales et alii, 20I7), ponen en estrecha relación la cerámica estilo Carambolo y la presencia fenicia en la península ibérica, primero a través de contactos comerciales y posteriormente por 
medio de las primeras colonias fundadas a finales del siglo Ix a. C. (Celestino y López-Ruiz, 2020: 343-344). Por tanto, la cerámica estilo Carambolo se entiende en un contexto cultural de contactos entre las poblaciones locales del suroeste y las del Mediterráneo oriental, destacando los fenicios entre estas últimas. Para acometer este objetivo se ha analizado la cerámica estilo Carambolo en aspectos como su distribución geográfica ya comentada, sus características tecnológicas, la decoración, sus orígenes y la cronología. Dentro del estudio tipológico se han tomado como referencia las denominaciones recogidas en las sistematizaciones al uso sobre la cerámica a mano del suroeste peninsular, principalmente la de Ruiz Mata (I995) o la de González de Canales et alii (2010), sin que ello suponga la asimilación del componente cronológico aparejado a la primera de ellas. Así, la cronología será abordada a partir de la datación de los estilos que inspiraron el origen de esta producción, la asociación de materiales o los resultados obtenidos de los análisis por ${ }^{14} \mathrm{C}$ sobre las muestras asociadas a cerámicas in situ.

\section{Caracterización tipológica y decorativa}

La cerámica estilo Carambolo se diferencia de otras producciones pintadas en rojo, como la cerámica estilo San Pedro II/Guadalquivir II, en la decoración o la tipología (Pellicer, 1979-80: nota 47; Blasco, 1980-198r: 91; Cabrera, 198r; Aubet, 1982: 387; Ruiz Mata, I984-I985). Así, mientras la cerámica estilo Carambolo desarrolló una decoración geométrica de tipo tectónico sobre recipientes de gran tamaño, la cerámica estilo San Pedro II optó por esquemas fundamentalmente radiales sobre formas típicas de la Primera Edad del Hierro, como las copas de paredes finas del tipo B.II de Ruiz Mata (I995). No obstante, las similitudes cromáticas de ambos estilos han llevado a algunas confusiones, con una general tendencia por clasificar en la cerámica estilo Carambolo todas las cerámicas a mano con decoración pintada en rojo sin tener en cuenta esta diferenciación, de ahí que en el mapa de distribución solo se hayan considerado los hallazgos publicados con representación gráfica que permiten su adscripción inequívoca a la cerámica estilo Carambolo. Algunas piezas del Guadiana Medio y la Beira Interior portuguesa también se han clasificado como cerámica estilo Carambolo, aunque existen diferencias morfológicas y decorativas que las desvinculan de esta producción. De hecho, en el último trabajo de conjunto sobre estos materiales portugueses, Vilaça et alii (2018: 70) han mostrado varias reservas en la adscripción inequívoca a la cerámica estilo Carambolo.

Las recientes excavaciones en el Bajo Guadalquivir han permitido ampliar el repertorio formal conocido hasta hace pocos años (Ruiz Mata, I984-I985: figs. I-3), destacando los conjuntos del Jardín de Alá, Huelva o El Carambolo.

Considerando todos los testimonios conocidos, se atestiguan formas abiertas entre las que destacan las cazuelas de carena alta marcada del tipo A.I de Ruiz Mata (1995), concretamente el tipo A.I.a (figura 2:I), A.I.b (figura 2:2) y A.I.e (figura 2:3). Otras cazuelas presentan una carena más suave (figura 2:4-7), correspondiente con el tipo A.II de este mismo autor. El total de las cazuelas representan el $27 \%$ de las formas registradas, con diámetros que oscilan entre los 18 y $42 \mathrm{~cm}$. Los cuencos, asimilables al tipo B.I de Ruiz Mata (1995) o 1C y $2 \mathrm{C}$ de González de Canales et alii (20ro), suelen ser versiones reducidas de las cazuelas (figura 2:8-9), a excepción del cuenco hemisférico hallado en el Jardín de Alá (figura 2:Io) y clasificado como forma $2 \mathrm{E}$ de González de Canales et alii (2010). Todos tienen paredes más delgadas con respecto a las cazuelas y diámetros que se sitúan entre los in y I6 cm, representando tan solo el 2,3 \% del total de formas. Los platos (figura 2:II-I2), con la proporción testimonial del I,56 \%, están muy fragmentados, pudiéndose constatar únicamente la forma de carena suave (figura 2:II). Entre los platos, establecidos por la relación entre el diámetro y su profundidad estimada, quizás se encuentre un borde engrosado hallado en el nivel XIIb de Setefilla a juzgar por su orientación (figura 2:I2).

Los recipientes cerrados, con un $69, \mathrm{I} 7 \%$, suponen la mayoría de formas registradas en la cerámica estilo Carambolo, como los vasos esferoides de borde entrante (figura 3:I), asimilables al tipo 7E de González de Canales et alii (20Io: fig. I4) y con una proporción del I,I7 \%. También se documentan los vasos elipsoides, con un $8,2 \%$ del total, algunos con 


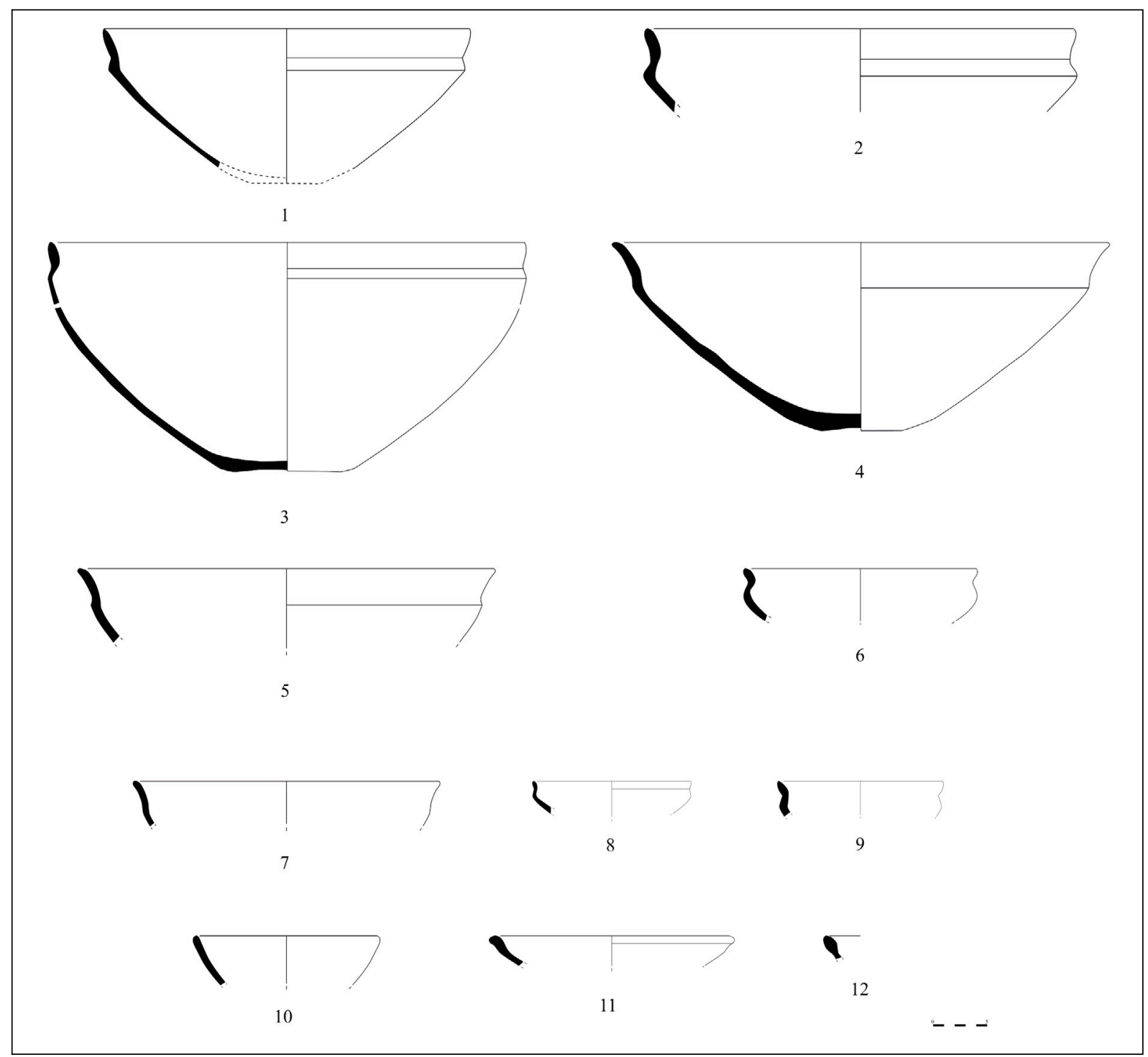

Figura 2. Formas abiertas de la cerámica estilo Carambolo. Cazuelas: 1-7 (Ruiz Mata, 1984-1985: fig. 1:1-2; Casado, 2015: figs. 131:1, 134:1,7; Carriazo, 1973: fig. 354). Cuencos: 8-10 (Casado, 2015: fig. 136; Hunt y García Rivero, 2017: fig. 34: JA-352_2). Platos: 11-12 (Murillo, 1994: fig. 4.70:1664; Aubet et alii, 1983: fig. 26:89)

Figure 2. Open shapes of the Carambolo style. Pot: 1-7 (Ruiz Mata, 1984-1985: fig. 1:1-2; Casado, 2015: figs. 131:1, 134:1,7; Carriazo, 1973: fig. 354). Bowls: 8-10 (Casado, 2015: fig. 136; Hunt and García Rivero, 2017: fig. 34: JA-352_2). Dishes: 11-12 (Murillo, 1994: fig. 4.70:1664; Aubet et al., 1983: fig. 26:89)

arranques de asa a la altura de los hombros (figura 3:2) que podrían corresponder con una de las formas que aparece en el Cabezo de San Pedro (Huelva) (Ruiz Mata, I995: fig. 29:I-7). El vaso elipsoide de fondo plano, que incluso llega a superar los $40 \mathrm{~cm}$ de diámetro, se clasifica, siguiendo la sistematización de Ruiz Mata (1995), como vaso E.I.a (figura 3:3) o E.I.b (figura 3:4). Sin embargo, la forma cerrada más representativa, con un 39,5\% del total, es el vaso bicónico del tipo A.I.f de Ruiz Mata (1995) (figura 3:5-6). Estos recipientes, resultado de la unión de una parte inferior hemisférica y otra superior troncocónica, muestran diámetros entre los 9 y los $35 \mathrm{~cm}$, por lo que existe una gran variabilidad en función de su tamaño o la posición más o menos elevada de la carena. Por último, se encuentran los soportes de carrete (figura $3: 7-8$ ), con un $20,3 \%$ de las formas totales registradas, utilizados muy probablemente para estabilizar en la superficie todos aquellos vasos bicónicos de base cóncava. Los soportes de carrete, con diámetros entre los I8 y $22 \mathrm{~cm}$, muestran dimensiones variables, destacando uno del santuario de E1 Carambolo 

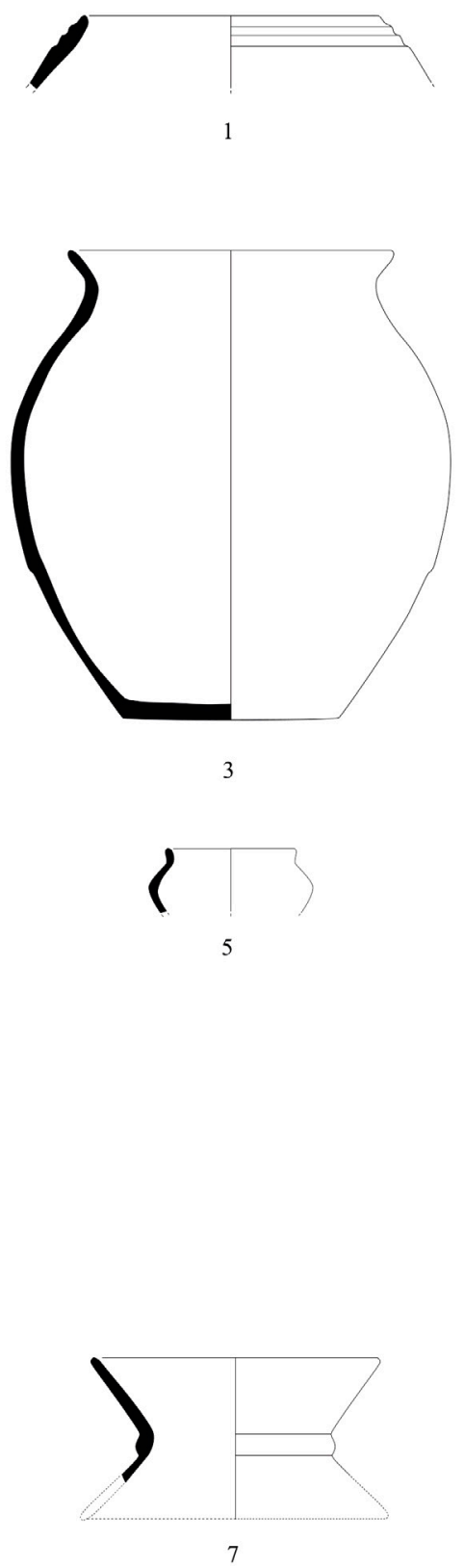
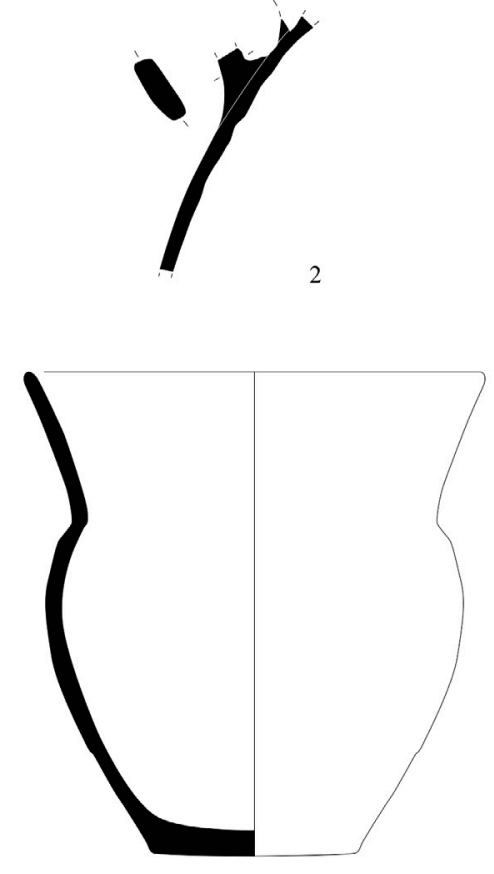

4
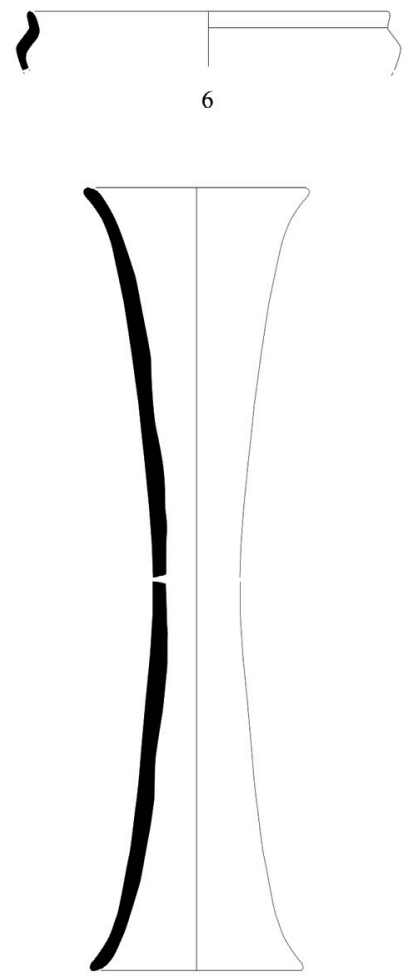

8

Figura 3. Formas cerradas de la cerámica estilo Carambolo. Recipiente esferoide: 1 (González de Canales et alii, 2004: lám. XXXIIl:13). Recipientes elipsoides: 2-4 (Casado, 2015: fig. 80:DJ/2002/24/13-54; Ruiz Mata, 1984-1985: fig. 1:4-5). Vasos Bicónicos: 5-6 (González Rodríguez et alii, 1995: lám. 1:7-8). Soportes de carrete: 7-8 (Ruiz Mata, 1984-1985: fig. 1:6; Casado, 2015: fig. 143:2)

Figure 3. Closed shapes of the Carambolo style. Spheroid shape: 1 (González de Canales et al., 2004: lám. XXXIII:13). Ellipsoid shape: 2-4 (Casado, 2015: fig. 80:DJ/2002/24/13-54; Ruiz Mata, 1984-1985: fig. 1:4-5). Biconical shape: 5-6 (González Rodríguez et al., 1995: lám. 1:7-8). Stand with spool form: 7-8 (Ruiz Mata, 1984-1985: fig. 1:6; Casado, 2015: fig. 143:2) 
por sus inusuales $67 \mathrm{~cm}$ de altura (figura r:8). Algunos tienen baquetón, de sección semicircular o apunta$\mathrm{da}$, que une los dos troncos de cono en su parte central, clasificándose como tipo D.I (Ruiz Mata, 1995).

En la cerámica estilo Carambolo la decoración, roja o violeta, es más compleja en la superficie externa, ya que la superficie interna no se decoró o simplemente desarrolló una homogénea capa de almagra o bandas horizontales de tintas planas (figura 4). Los motivos, aplicados a pincel, son de naturaleza geométrica (Ruiz Mata, I984-I985; Torres, 2002: I30-I35; Casado, 2015; 2019; Mederos, 2017), registrándose triángulos, rombos, cuadrados habitualmente divididos por la diagonal, aspas, zigzag, etc. Todos estos, casi siempre tramados en un número variable de líneas, suelen estar organizados en frisos horizontales o en sucesiones enmarcadas a través de bandas de líneas horizontales y verticales que ocasionalmente formaron metopas. También existieron motivos naturalistas (Buero, I984), como ánades, cápridos o cérvidos, ejecutados acorde al lenguaje geométrico que muestra esta producción y la cultura material del momento, como la eboraria (Torres, 2002: fig. X.I) o las estelas de guerrero (Celestino, 200I). El color rojo se obtuvo, como revelan los análisis de Difracción de Rayos X-Policristal (DRX-P) de otras cerámicas pintadas de la Primera Edad del Hierro (Celestino et alii, 2018: 145), a partir de hematites, es decir, óxidos de hierro que se mezclarían con algún aglutinante para lograr la pintura.

E1 repertorio decorativo de la cerámica estilo Carambolo fue relacionado desde los primeros estudios con el Geométrico griego, lo cual permitió una aproximación cronológica a partir de la datación del estilo en el que se inspiraría. Siguiendo la periodización de Coldstream (I968: 330), hubo autores que señalaron paralelismos con el Geométrico Antiguo y Medio (Almagro-Gorbea, I977: I2O-I25; Cabrera, I98r: 328), el Geométrico Medio II (Bendala, 1979: 37-38; Ruiz Mata, I984-1985: 242; González de Canales et alii, 20ro: 657) o el Geométrico Final (Pellicer, I969: 295), aunque otros investigadores prefirieron vincular el estilo Carambolo con la cerámica del tipo Bichrome IV del Chipriota Arcaico I (Maluquer de Motes, I960: 286-287; Schubart, I971: 169). Recientemente también se ha valorado el repertorio geométrico del mundo Atlántico, por lo que, si existió alguna aportación del mundo griego, debería corresponder con el periodo Protogeométrico (Mederos, 20I7). En efecto, existen temas de la orfebrería atlántica muy similares a la cerámica estilo Carambolo (Almagro-Gorbea, I977: figs. 4, 6), aunque actualmente se cuenta con escasos hallazgos en el suroeste para establecer una relación directa e inequívoca entre el geometrismo atlántico y el origen de la cerámica estilo Carambolo. La cerámica de retícula bruñida, coetánea a la cerámica estilo Carambolo, muestra una decoración de tipo geométrico, aunque los esquemas radiales que la caracterizan, restringidos a la superficie interna, son completamente ajenos a la sintaxis decorativa del estilo Carambolo. Mayor similitud comparte con la cerámica esgrafiada o grabada, coetánea a la cerámica estilo Carambolo en el yacimiento homónimo desde la fase $\mathrm{V}$ (Casado, 20I5: 168), si bien ambas producciones parecen incluirse dentro del mismo fenómeno geométrico, aunque desarrollado con técnicas diferentes.

\section{Cronología convencional y absoluta}

Las concomitancias estilísticas apuntadas han dado lugar a algunas propuestas cronológicas que se pueden agrupar en dos tendencias, una que defiende el desarrollo de la cerámica estilo Carambolo durante el siglo ix hasta el 750 a. C. (Almagro-Gorbea, I977: I23-I24; Abad, I979: 178; Bendala, 1979: 35; Fernández Miranda, 1979: 52; Blasco, 1980-1981: 78; Cabrera, 1981: 329; Aubet, 1982: 387; Ruiz Mata, 1984-1985: 242-243; Fernández Jurado, I988-1989: 209; Torres, 2002: 134) y otra que apunta hacia la segunda mitad del siglo viII a. C. y el primer cuarto del siglo vir a. C. (Pellicer, I979-1980: 329; Pellicer et alii, I983: 75; Amores, 1995: 165-166; Schattner, 2000: 7I), aunque Pellicer (2006: 28) optó finalmente por fechar esta producción entre los siglos X-viIr a. C. Otros investigadores han retrotraído el límite superior hasta finales del siglo $\mathrm{x}$ a. C. (Werner, 1990: 43; Brandherm, 2008: IoI; Fernández Gómez y Buero, 2010: 82) o incluso mediados del siglo XII a. C. (Castro et alii, 1996: 198-199; Mederos, 20I7: II9). 

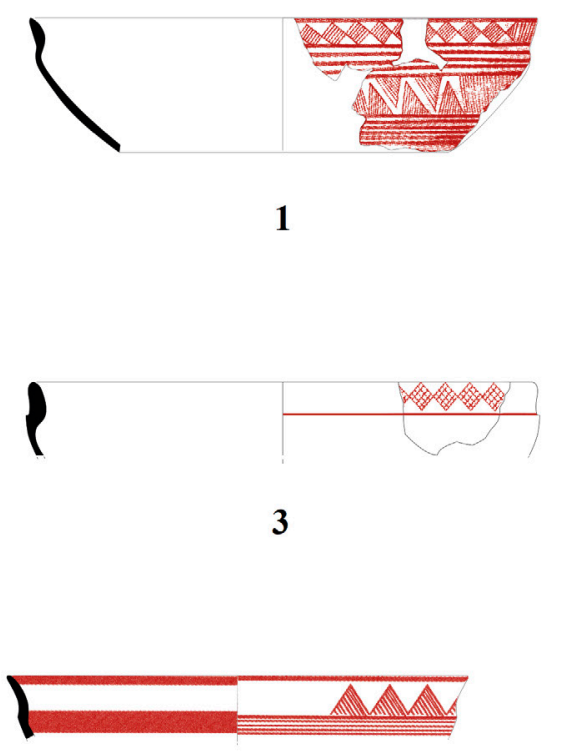

5

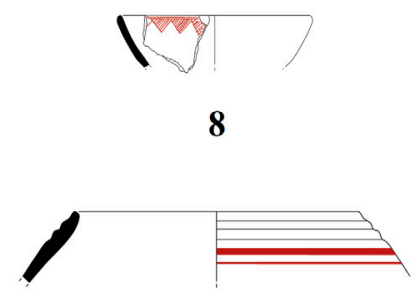

10

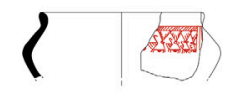

12

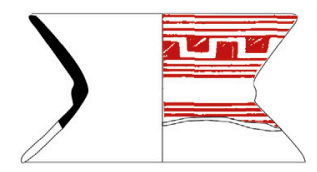

14
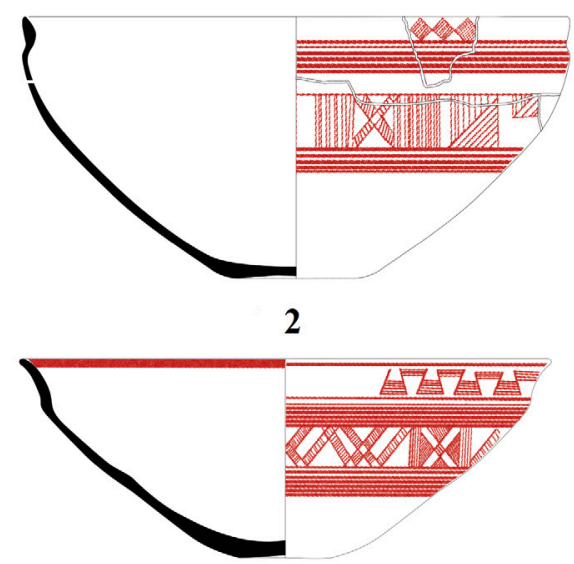

4

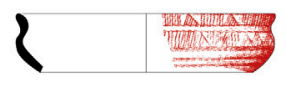

6

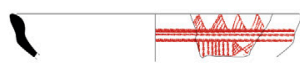

9

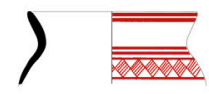

11

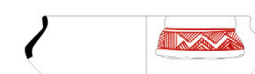

13

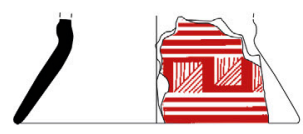

15

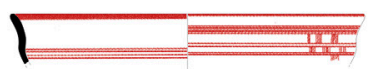

7

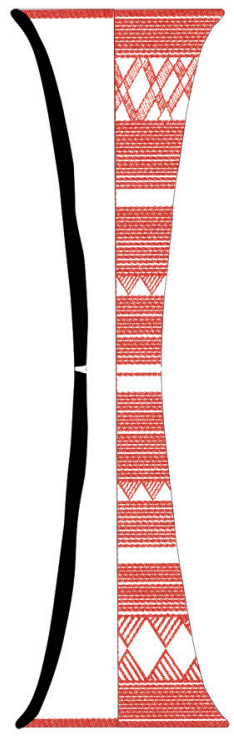

16

Figura 4. Selección de formas de la cerámica estilo Carambolo. Cazuelas: 1-7 (Carriazo, 1973: fig. 354: arriba; Casado, 2015: figs. 51:DJ/2002/24/2544; 56:DJ/2002/24/1025-25+27+28+29; 66; 67:DJ2002/24/2405-88+89; 114:DJ2002/24/1007; Carriazo, 1973: fig. 355: izquierda). Cuenco: 8 (Hunt y García Rivero, 2017: fig. 34:JA-352_2). Plato: 9 (Casado, 2015:

fig. 86:DJ2002/24/15-140, 177). Vaso esferoide de borde entrante: 10 (González de Canales et alii, 2004: lám. XXXIII:13). Vaso elipsoide: 11 (González de Canales et alii, 2004: lám. XXXIl:16). Vasos bicónicos: 12-13 (González Rodríguez et alii, 1995: lám. 1:8; Ruiz Mata, 1984-1985: fig. 3:1). Soportes de carrete: 14-16 (Ruiz Mata, 1984-1985: fig. 1:6-7; Casado, 2015: fig. 99)

Figure 4. Selected shapes of the Carambolo style. Pots: 1-7 (Carriazo, 1973: fig. 354: above; Casado, 2015: figs. 51:DJ/2002/24/2544; 56:DJ/2002/24/1025-25+27+28+29; 66; 67:DJ2002/24/2405-88+89; 114:DJ2002/24/1007; Carriazo, 1973: fig. 355: left). Bowl: 8 (Hunt and García Rivero, 2017: fig. 34:JA-352_2). Dish: 9 (Casado, 2015: fig. 86:DJ2002/24/15-140, 177). Spheroid shape with leading edge: 10 (González de Canales et al., 2004: lám. XXXIII:13). Ellipsoid shape: 11 (González de Canales et al., 2004: lám XXXIl:16). Biconical shape: 12-13 (González Rodríguez et al., 1995: lám. 1:8; Ruiz Mata, 1984-1985: fig. 3:1). Stand with spool form: 14-16 (Ruiz Mata, 1984-1985: fig. 1:6-7; Casado, 2015: fig. 99) 
Las recientes excavaciones en El Carambolo han vuelto a plantear una cronología más reciente para esta producción (Casado, 2015: 138-I48), ya que el «fondo de cabaña» de Carriazo corresponde a una fosa ritual de la fase III del santuario, fechada entre finales del siglo viII y mediados del siglo vir a. C. (Fernández Flores y Rodríguez Azogue, 2007: 125-154). Torres (2016) ha propuesto la existencia de dos fosas insertas en dos periodos distintos, adscribiendo la cerámica estilo Carambolo a una fosa del Bronce Final que, según su interpretación, sería previa a la construcción del primer santuario y constituida por los niveles inferiores de Carriazo (Carambolo V).

La información que ofrecen los materiales asociados en contextos in situ, abogan por una datación de la cerámica estilo Carambolo de entre finales del siglo Ix y poco después de mediados del siglo viI a. C. Por tanto, estaría en consonancia con la cronología tradicional del Geométrico Medio II y los primeros momentos del Geométrico Final griego (Coldstream, 1968: 330), aunque la revisión de la cronología absoluta radiocarbónica de ambos estilos (García Alfonso, 2016; 20I7), como se viene reivindicando desde hace tiempo (Brandherm, 2008), elevarían el límite superior hasta mediados del siglo Ix cal. a. C.

En yacimientos como Concepción 3 (González de Canales el alii, 2017) y Útica (López Castro et alii, 2016) la cerámica estilo Carambolo se halla en asociación estratigráfica con cerámicas áticas del Geométrico Medio II, reforzando este marco cronológico establecido entre los siglos IX-VIII a. C. Dicha cronología queda igualmente representada en algunas muestras analizadas para la obtención de fechas radiocarbónicas en contextos en los que se ha hallado cerámica estilo Carambolo ( $\mathrm{Me}-$ deros, 2017: fig. 15), destacando la muestra de vida corta analizada (diente humano) en el fondo J de Jardín de Alá que ofrece una cronología ante quem para la cerámica estilo Carambolo al hallarse en un contexto más reciente a los niveles en los que se documentó esta producción (Hunt y García Rivero, 20I7: figs. 4I y 42), concretamente una cronología que se centra en el siglo ix cal. a. C. Las muestras de carbón analizadas en los niveles fundacionales de El Carambolo (Fernández Flores y Rodríguez
Azogue, 2007: fig. 14) ofrecen, por su parte, una cronología de finales del siglo Ix a. C. o principios del siglo vili a. C. para el Carambolo V y, por extensión, para la cerámica estilo Carambolo hallada in situ dentro de esta fase. Pese a ello, existen grandes dificultades para concretar una datación radiocarbónica fiable, ya que la mayor parte de las muestras analizadas pertenecen a carbones que pueden estar sometidos al efecto de «madera vieja» (Renfrew y Bahn, 2008: 236), por lo que los contextos podrían ser más recientes a los que indican los porcentajes de las muestras analizadas. A ello habría que añadir la inestabilidad que muestra la curva de calibración a partir del 800 cal. a.C. a causa del evento climático o,85k Yrs BC (Urbina y Morín, 20I7: 25), ofreciendo márgenes muy amplios que suponen un problema para acotar límites cronológicos.

En la península ibérica se han constatado cerámicas griegas del Geométrico Medio II en yacimientos en los que también se ha documentado cerámica estilo Carambolo, como en Méndez Núñez 7-г3/Plaza de las Monjas I2 (González de Canales et alii, 2004: láms. XVIII-XIX) o en el propio Carambolo (Fernández Flores y Rodríguez Azogue, 2007: lám. 9 derecha), aunque, como se indicó más arriba, solo en el caso de Concepción 3 podría asegurarse su asociación estratigráfica (González de Canales et alii, 20I7: pl. XV:I-3a). Tal circunstancia, como apoyan los paralelos iconográficos o la tendencia por focalizar la decoración en la mitad superior del recipiente, permite poner en relación la decoración de la cerámica estilo Carambolo con el Geométrico Medio II griego, aunque algunos temas del Geométrico Final también se introdujeron dada su parcial contemporaneidad y las semejanzas de algunos de sus motivos con la cerámica estilo Carambolo, como las filas de ánades (Coldstream, I968: pl.r3:a; Buero, I984: figs. r:4; 3:2; 6:b). Ello explicaría que la cerámica estilo $\mathrm{Ca}^{-}$ rambolo surgiera como una producción plenamente configurada (Ruiz Mata, I984-1985: 237), sin tanteos previos, lo cual aboga por la existencia de un estilo plenamente configurado que sirvió de modelo de inspiración a través de su observación directa.

No obstante, y en ese contexto de interacción comercial en el que llegaron productos procedentes del 
Mediterráneo oriental a la península ibérica, cabría suponer la existencia de productos perecederos que no han dejado huella arqueológica, como telas o maderas en las que se plasmaría el mismo lenguaje decorativo que conservan las cerámicas (Buero, 1987: 45; Ruiz-Gálvez, 1993: 56; Cáceres, I997: I25-I40). De hecho, el número de cerámicas griegas geométricas halladas en la península ibérica es aún escaso para explicar, por sí mismas, el origen de la decoración de la cerámica estilo Carambolo.

De esta forma, y según la cronología radiocarbónica de la colonización fenicia en la península ibérica a finales del siglo ix cal. a. C. (Torres, 2008: I40), la cerámica estilo Carambolo se desarrolló en un periodo de transición del Bronce Final a la Primera Edad del Hierro. Por tanto, según el modelo propuesto por Alvar (2008), esta producción surgió en un contexto de contacto no hegemónico entre las poblaciones locales del suroeste y las poblaciones fenicias, caracterizado por intercambios de tipo comercial y contactos previos a la presencia estable fenicia como consecuencia de la colonización. Estos contactos culturales suponen el contexto y el medio por el que las poblaciones locales conocieron una tradición geométrica de tipo griego que reformularon en su propia tradición vascular, aunque en la actualidad no se sabe con seguridad si a través de los fenicios, que pudieron incorporar cerámicas griegas geométricas entre sus cargamentos para su comercialización en Occidente, o por la posible intervención eubea que participaría directamente en este comercio, lo cual no implicaría una colonización griega para tales cronologías. La asociación de cerámicas griegas geométricas a otros materiales de tipo fenicio en el suroeste peninsular ha llevado a un mayor número de autores a decantarse hacia la primera opción, si bien las trayectorias comerciales llevadas a cabo por los eubeos en el Mediterráneo hacen perfectamente viable la presencia directa griega para estas cronologías. La cerámica estilo Carambolo continuó vigente durante la Primera Edad del Hierro, en un contexto plenamente colonial en el que existió una presencia estable fenicia.

En todo caso, la cerámica estilo Carambolo es fruto de un estímulo externo que las poblaciones locales del suroeste adaptaron a sus propios gustos y concepciones bajo un proceso de reformulación, por lo que, en el estado actual de la investigación, parece inviable seguir manteniendo un origen en la tradición geométrica peninsular para la cerámica estilo Carambolo. Esto no invalida que esta producción entrara en coherencia con los gustos de las comunidades locales del suroeste, acostumbradas a un lenguaje geométrico en sus manifestaciones artísticas. De hecho, la acogida de la decoración geométrica griega para el desarrollo de la cerámica estilo $\mathrm{Ca}^{-}$ rambolo, ya sea por intermediación fenicia o eubea, se entiende en el contexto de unos gustos geométricos por parte de las comunidades locales que la desarrollaron, si bien este geometrismo suponía una novedad en cuanto a la sintaxis decorativa o los motivos ejecutados.

\section{Proceso de elaboración y analíticas por DRX}

La cerámica estilo Carambolo fue elaborada a mano, aunque algunos autores señalaron su posible fabricación a torno lento o «a la rueda» (Carriazo, 1973: 502; Cabrera, 198r: 32I). Como recientemente ha señalado Casado (2015: 77-81; 20I9: I4), el torno debe entenderse como un sistema mecánico que emite una fuerza centrífuga para el modelado de la pieza. Dicha tecnología dejaría unas marcas en las superficies que no se detectan en esta cerámica, aunque admite la posible existencia de algún elemento para ejecutar la decoración, como esteras o algún instrumento rotatorio como ya apuntaron Buero y Fernández Gómez (2010: 53). En todo caso, la pieza ya estaría modelada, lo que desaconseja el uso inapropiado de «torno lento». En cuanto al posible uso de moldes (Buero y Fernández Gómez, 2010: 52-53), dicha consideración parece responder a la adscripción al estilo Carambolo de algunas piezas que realmente pertenecen al estilo San Pedro II y en la que ya se planteó el uso de moldes (Cabrera, I98r: 322).

Esta cerámica se caracteriza por tener una fábrica de granulometría fina, con tonos que oscilan entre el marrón oscuro o negro y el castaño claro. Las cocciones son frecuentemente reductoras o alternas, apreciándose en este último caso un núcleo 


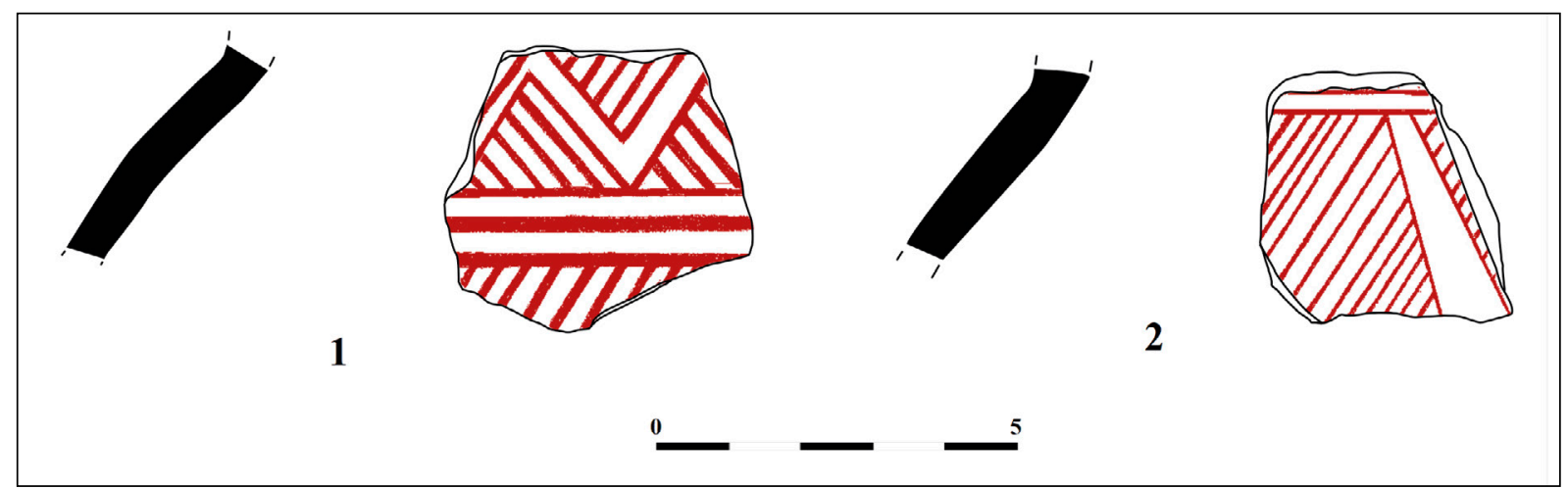

Figura 5. Fragmentos de vasos bicónicos del Cerro Macareno: M-1 y M-2

Figure 5. Fragments of biconical shapes from Cerro Macareno: M-1 and M-2

gris o negro. Las superficies, con gamas entre el negro y beige, suelen recibir un tratamiento bruñido de gran calidad, aunque las superficies internas de las formas cerradas fueron ocasionalmente descuidadas con un ligero alisado.

Pese al gran interés que la cerámica estilo $\mathrm{Ca}^{-}$ rambolo ha despertado en la investigación desde el momento de su descubrimiento, tan solo se cuenta con un análisis arqueométrico. Los análisis por Difracción de Rayos X (DRX), Microscopía Electrónica y Espectroscopía Infrarroja fueron efectuados sobre un soporte del tipo D de Ruiz Mata (1995) hallado en el corte A.2 del Cabezo de San Pedro en Huelva (Galván, 1986: 283). La muestra (M.23) determinó la presencia de cuarzo, filosilicatos (montmorillonita), feldespato, tremolita, calcita y mica. De esta composición destaca la tremolita, un mineral típico de la actual provincia de Sevilla que determinó el origen exógeno de la pieza onubense (Galván, I986: 296-297, 3II), lo que llevó a suponer la existencia de un único centro de producción ubicado en el entorno de Sevilla, concretándose incluso en el yacimiento de El Carambolo (Casado, 2003: 292).

Con el objetivo de arrojar luz sobre esta cuestión, se han analizado por DRX dos fragmentos de cerámica estilo Carambolo procedentes del Cerro Macareno (La Rinconada, Sevilla) (figuras 5-6), aunque hay que reconocer las limitaciones de interpretación al no contar con análisis petrográficos y químicos. Estas limitaciones se hacen más evidentes si se tiene en cuenta la restricción de los análisis a dos únicos fragmentos, aunque en el contexto de esta producción resultan relevantes. Dichos fragmentos fueron depositados en la escuela de formación profesional de San José de La Rinconada (Almagro-Gorbea, 1977: nota I48; Pellicer y Amores, 1985: 140), aunque en la actualidad se encuentran en la colección de referencia de la Universidad Complutense de Madrid. Ambas piezas, de las que se desconoce su localización exacta en el yacimiento, corresponden a dos vasos bicónicos. Muestran una fábrica marrón y grisácea por cocción oxidante, aunque en una se aprecia un nervio por cocción alterna. Las superficies son marrones, las internas alisadas y las externas con un sobresaliente bruñido sobre el que se aplicó una decoración geométrica pintada en color violeta, compuesta por una sucesión de triángulos tramados invertidos $\mathrm{y}$ con el vértice hacia arriba que ofrecen un meandro en reserva.

El yacimiento de Cerro Macareno, situado en la orilla izquierda del Guadalquivir, se localizaba originalmente sobre un suave promontorio formado por las propias terrazas del mismo. Los niveles más antiguos que se han registrado hasta la actualidad en el yacimiento datan de la segunda mitad del siglo viII a. C. (García Fernández, 2020: II9), por lo que, según la datación de esta producción, los dos fragmentos de cerámica estilo Carambolo pertenecerían a una fase más antigua aún sin registrar o a los últimos momentos de esta producción.

De cada fragmento analizado ${ }^{1}$ se ha extraído un gramo para la preparación de las muestras denominadas M-r y M-2 (figura 6). Se acometió el análisis

1 Analíticas realizadas por el doctor David Guirao Polo. 

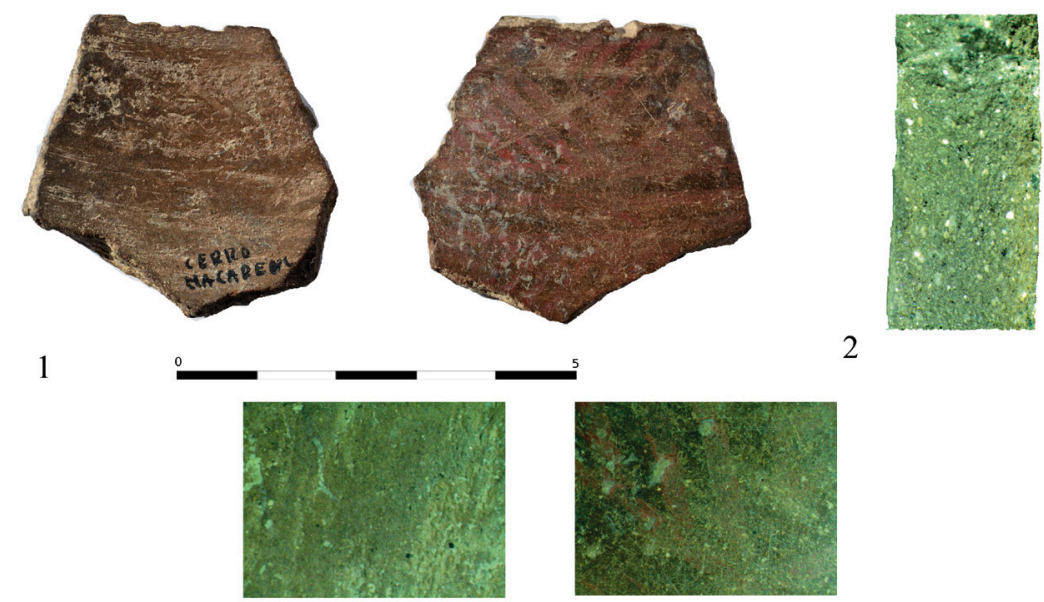

2

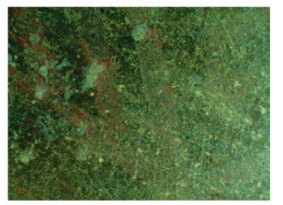

3

4

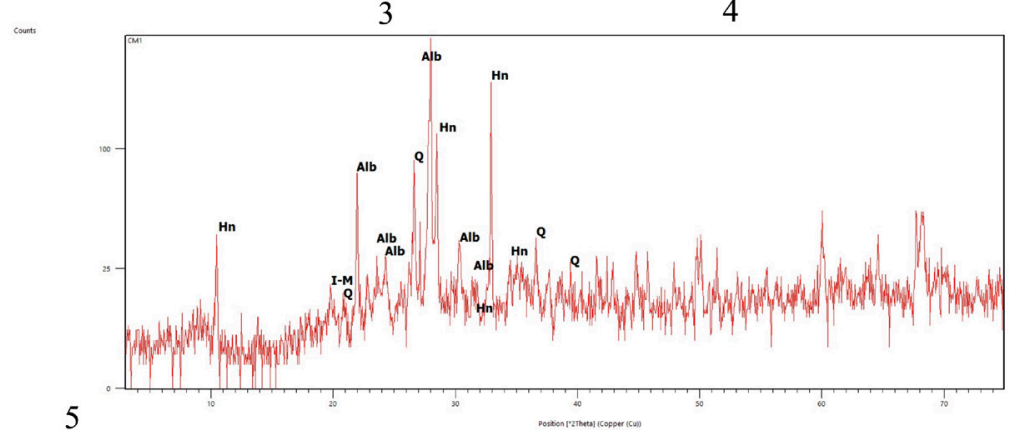

5
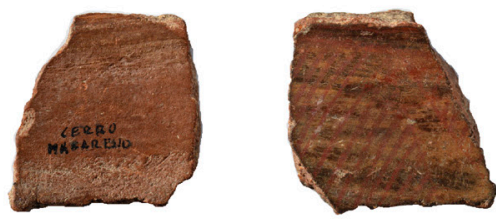

6
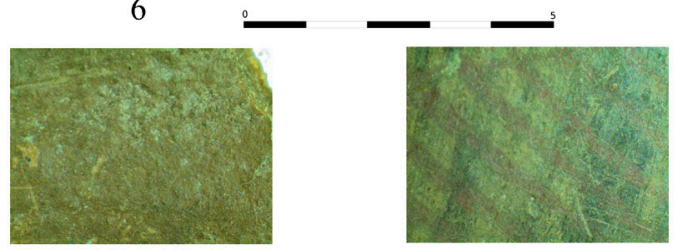

7
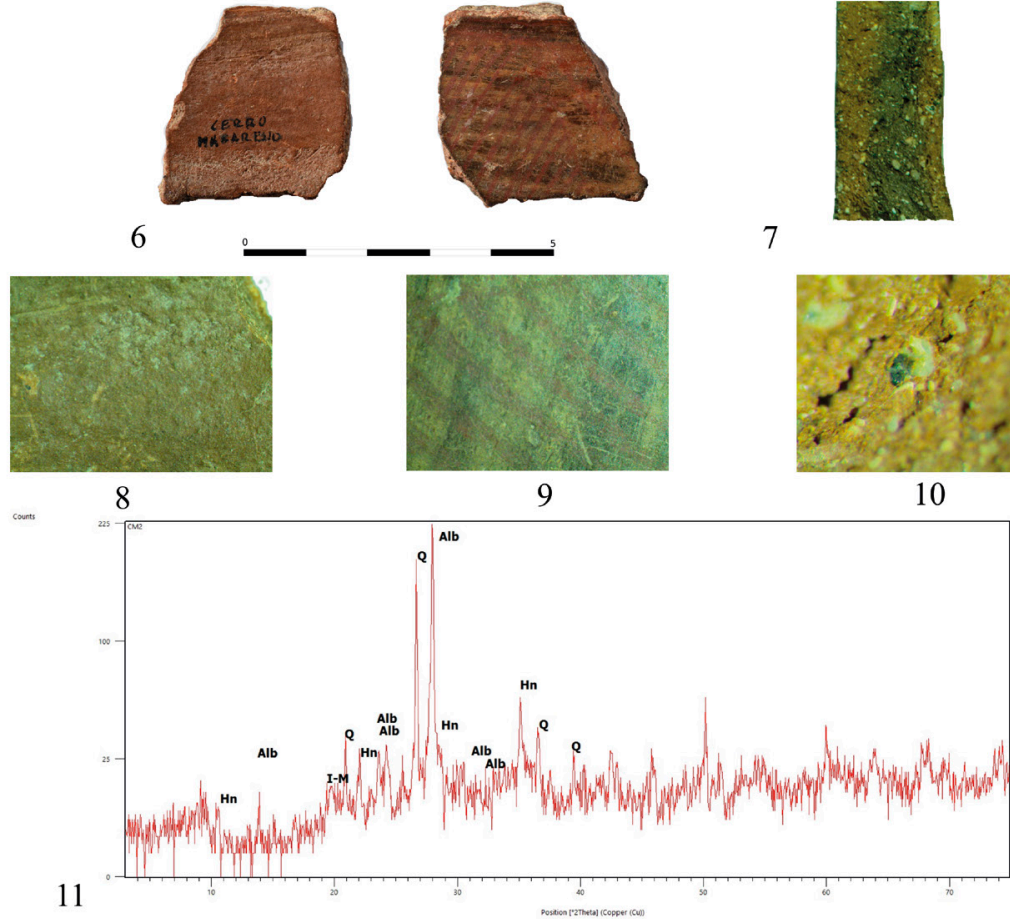

Figura 6. Cerámicas estilo Carambolo de Cerro Macareno analizadas por DRX. CM-1: 1, 3-4. Fotografías y detalles de las superficies interna y externa respectivamente. 2. Sección. 5. Difractograma. CM-2: 6, 8-9. Fotografías y detalles de las superficies interna y externa respectivamente. 7. Sección. 10. Detalle de sección con piroxeno. 11. Difractograma. Difractogramas del doctor David Guirao Polo

Figure 6. Carambolo style fragments from Cerro Macareno analyzed by XRD. CM-1: 1, 3-4. Photographs and details of the internal and external surfaces respectively. 2. Section. 5. Diffractogram. CM-2: 6, 8-9. Photographs and details of the internal and external surfaces respectively. 7. Section. 10. Detail of section with pyroxene. 11. Diffractogram. Diffractograms of David Guirao Polo (PhD) 
mineralógico, o por DRX, en el laboratorio IRICA de la Universidad de Castilla-La Mancha, unos análisis no cuantitativos que solo permiten conocer los minerales detectados. Los resultados obtenidos han revelado la presencia de cuarzo (Q), filosilicatos del grupo de las illitas-montmorillonitas (I-M), albita $(\mathrm{Al})$ y hornblenda $(\mathrm{Hn})$. La albita, una plagioclasa del grupo de los silicatos, indica una temperatura de cocción en torno a los $850^{\circ} \mathrm{C}$ (Guirao, 20I4: I4O-I4I), mientras que la calcita de la muestra $\mathrm{M} .23$ del Cabezo de San Pedro rebajaría este límite hasta los 700-750 ${ }^{\circ} \mathrm{C}$, ya que es un mineral que desaparece a partir de estos límites (Guirao, 20I4: I39). Así, la temperatura de cocción de esta cerámica debió situarse entre los $700-850^{\circ} \mathrm{C}$, desconociéndose el tipo de estructura empleada. Algunos autores han sugerido la existencia de hornos básicos formados por simples hoyos en el suelo en los que se depositó el combustible junto a las piezas (Buero, 1987: 39).

Por otro lado, las dos muestras contienen hornblenda, un mineral de origen magmático asociado a rocas ígneas y metamórficas, por lo que se trata de un elemento propio de las regiones volcánicas. La hornblenda se ha atestiguado en otras cerámicas tartésicas de Ategua (Córdoba), poniéndose en relación con el comercio con otras regiones en las que se ha registrado este mineral, como Sierra Morena o Sierra Nevada (Barrios et alii, 2010: 370, fig. I4), aunque la distribución de la cerámica estilo Carambolo descartaría su elaboración en la región de Sierra Nevada. Por otro lado, en el yacimiento de El Trastejón, situado en la Sierra de Aracena (Huelva), se han documentado algunas cerámicas con olivino (Polvorinos del Río, 2oro: tab. 7.2.a) que estaría revelando un entorno de naturaleza volcánica. Por tanto, es posible que las cerámicas estilo Carambolo del Cerro Macareno fueran fabricadas en el entorno onubense desde donde fueron comercializadas a Cerro Macareno, dado que el comercio de esta producción entre ambas regiones ya lo planteaba el soporte de carrete del Cabezo de San Pedro proviene del Aljarafe sevillano (M.23). Sin embargo, también hay que tener en cuenta la colmatación de sedimentos de Sierra Morena en el valle del Guadalquivir como consecuencia de la erosión producida por los afluentes del río (Torres, 2002: 47). Así, los minerales de naturaleza volcánica de Sierra Morena podrían haberse transportado al valle del Guadalquivir por diversos agentes naturales y, por tanto, las cerámicas estilo Carambolo de Cerro Macareno podrían haberse realizado en el propio yacimiento sevillano.

En todo caso, los resultados por DRX de las muestras M.23 del Cabezo de San Pedro y M-r y M-2 de Cerro Macareno revelan una naturaleza mineralógica distinta y, por lo tanto, una procedencia diferente de las piezas. Estos datos mineralógicos estarían confirmando la existencia de varios centros de producción para la elaboración de la cerámica estilo Carambolo, como era de esperar dada su cantidad y dispersión (figura I), entendiendo como centro de producción el lugar de elaboración cerámica. La información disponible no permite determinar aspectos tan interesantes como las características de estos centros de producción, la reconstrucción del proceso productivo o el número de artesanos que pudieron trabajar en cada uno de ellos.

\section{Uso, funcionalidad y significado}

En lo relativo al uso, la extraordinaria calidad de esta cerámica ha llevado a relacionarla con la vajilla de lujo para el desarrollo de banquetes en los que se visualizó el prestigio de la élite social (Almagro-Gorbea, I986: 427-428). Es posible que en estos banquetes se consumiera algún tipo de bebida alcohólica (Torres, 2002: 135), probablemente vino si se considera la intensificación de vitis vinifera desde los primeros contactos con las poblaciones fenicias, como atestiguan las semillas de Méndez Núñez 7-I3/ Plaza de las Monjas I2 (González de Canales et alii, 2oro: fig. 4 izquierda) o la constatación de un viñedo en el yacimiento de Orden-Seminario (Huelva) en la transición del siglo IX al viıI cal. a. C. (Pérez Jordá et alii, 20I7: 535).

Otros autores, en cambio, han planteado el uso de esta cerámica para cultos solares (Buero, I987: 46-47) o para ceremonias referentes a una divinidad relacionada con la fertilidad y la regeneración del ciclo vital (Buero, 1984: 363-364; 1987), identificada por algunos con Astarté (Belén y Escacena, 2002: I68; Casado, 2003; 2015: 245-246). 
Una tercera postura reúne las dos anteriores al plantear el uso de la cerámica estilo Carambolo tanto para fines religiosos como para actos sociales de corte elitista (Torres, 2002: 135), por lo que no sería una cerámica para un fin determinado.

En cuanto al uso práctico de estos recipientes, es posible que, como se ha valorado recientemente para algunas cerámicas bícromas de la Primera Edad del Hierro (Celestino et alii, 20r8: 135), los vasos estuvieran en uso y se decoraran ex professo para algún tipo de ceremonia en la que se amortizaría la vajilla en un posible acto ritual. Esta idea quizás quede atestiguada en las marcas de uso que presentan algunos soportes de carrete (Buero, 1987: 38), ya que la existencia de esta frágil decoración contradice un uso prolongado. Sin embargo, como ocurre con otras cerámicas a mano con decoración pintada en las que se aplicó una capa de cera de abeja (García Huerta, 20I9: Anexo II; Sánchez et alii, 20I9), también es posible que se utilizara algún elemento orgánico con el fin de salvaguardar la decoración sin ocultarla, impidiendo así el consumo del pigmento rojo en aquellos vasos con la superficie interna decorada. Dicha capa aseguraría la impermeabilidad de esta superficie sin sacrificar la decoración, evitando con ello la intoxicación del comensal al emplear el vaso, aunque sería una hipótesis difícil de mantener dada la ausencia de análisis de contenido en cerámicas estilo Carambolo. Es posible que esta capa transparente de cera también se aplicara en la superficie externa para adherir bien la pintura, ya que el segundo bruñido empleando un canto de río, como han sugerido algunos autores (Buero, 1987: 39; Buero y Fernández Gómez, 20Io: 53), supondría la total desaparición de la decoración.

\section{Conclusiones y valoración final}

La cerámica estilo Carambolo fue una producción a mano que se desarrolló en el Bajo Guadalquivir durante la transición del Bronce Final a la Primera Edad del Hierro, concretamente entre finales del siglo ix y poco después de mediados del siglo viır a. C. en cronología convencional y entre mediados del siglo IX y principios del siglo viII cal. a. C. en cronología absoluta radiocarbónica. Este marco temporal, unido a los paralelos iconográficos y compositivos, permite relacionar la decoración de la cerámica estilo Carambolo con el Geométrico Medio II y el Geométrico Final griego como ya apuntaron algunos autores. Dicha relación parece reforzarse por la presencia de cerámicas griegas de estos estilos en el suroeste peninsular, destacando las del Geométrico Medio II en yacimientos en los que se ha registrado cerámica estilo Carambolo, aunque son escasas las que presentan una asociación estratigráfica. No obstante, el número de fragmentos es aún escaso para explicar por sí mismo el origen de la cerámica estilo Carambolo, por lo que debieron de existir objetos foráneos con decoración geométrica que no han dejado huella arqueológica y que también pudieron intervenir en la configuración de este estilo típico del Bajo Guadalquivir.

El surgimiento de la cerámica estilo Carambolo y su relación con el Geométrico griego debe entenderse en ese contexto de relaciones comerciales y culturales entre las poblaciones foráneas y las poblaciones locales del suroeste durante la transición del Bronce Final a la Primera Edad del Hierro, una actividad comercial que reflejan los conjuntos de Méndez Núñez 7-I3/Plaza de las Monjas i2 (González de Canales et alii, 2004) o Concepción 3 (González de Canales et alii, 20I7).

Este ambiente de interacción comercial y cultural configuró el contexto de la llegada y aceptación del geometrismo griego por las poblaciones locales del suroeste, aunque este fenómeno se caracterizó por un proceso de reformulación en el que dichas poblaciones ejecutaron esta decoración geométrica sobre formas típicas de su tradición vascular dando lugar a la cerámica estilo Carambolo. Esta tradición vascular se retrotrae al Bronce Final, como recientemente han demostrado las fechas calibradas de la necrópolis de Setefilla para formas tan características de este estilo como el vaso bicónico (Brandherm y Krueger, 20I7: fig. 6). Algunas características técnicas, como las cocciones reductoras o las superficies bruñidas, también remiten a las tradiciones locales del Bronce Final. El hecho de que la decoración que caracteriza a la cerámica estilo Carambolo se ejecute sobre formas típicas del Bronce Final no implica 
su pleno desarrollo en este periodo, ya que los contextos estratificados reflejan su producción durante la transición del Bronce Final al Hierro I y durante el Hierro I. De hecho, la cerámica estilo Carambolo se desarrolló sobre algunas formas tradicionalmente consideradas más recientes, como las cazuelas de carena suave del tipo A.II de Ruiz Mata (I995). Aun así, ya Belén (20or: 46) advirtió sobre la continuidad de formas típicas del Bronce Final en momentos posteriores, aunque con porcentajes mucho más reducidos con respecto a esta fase.

De esta forma, la cerámica estilo Carambolo surge como una producción original, híbrida y adaptada a las concepciones de las poblaciones locales del suroeste peninsular, verdaderas protagonistas en la creación de esta producción. Esta hibridación surge como consecuencia de la conjunción entre unas formas locales que remiten a la tradición alfarera del Bronce Final y a una decoración geométrica foránea. Para su elaboración existieron, al menos, dos centros de producción, como han revelado los análisis mineralógicos, aunque, en función de la cantidad y la distribución de esta cerámica, cabe deducir la vigencia de varios centros artesanales localizados en el Bajo Guadalquivir. Es posible que, en el futuro, cuando se disponga de un mayor número de datos, se puedan diferenciar tendencias o comportamientos estilísticos concretos en determinadas regiones o centros de producción, aproximándonos incluso al concepto «taller» en el que se puedan concretar maestros o escuelas.

En lo relativo a las causas por las que las poblaciones locales del suroeste tomaron el estilo geométrico griego como fuente de inspiración para la configuración de la cerámica estilo Carambolo sería una cuestión más difícil de abordar, aunque posiblemente tenga su explicación en la escasez de cerámicas griegas geométricas que revela el registro arqueológico. Esta escasez quizás favoreció la concepción de estas cerámicas como un bien limitado y, por lo tanto, de acceso muy restringido. De esta forma, es muy probable que se hubiera relacionado la idea de prestigio con el geometrismo griego, sobre todo si se tiene en cuenta su conocimiento a través de piezas adquiridas por vía comercial y, por lo tanto, asociadas al exotismo que conlleva una importación.

Por otro lado, se observa cómo el Geométrico griego entró en coherencia con los gustos geométricos que imperaban en la transición del Bronce Final-Hierro I, como atestiguan las estelas de guerrero en las que las élites quedaron representadas (Celestino, 200I). Así, y aunque se trata de una decoración foránea, no contradecía las tradiciones ancestrales de las poblaciones locales del suroeste, por lo que fue una decoración que reinterpretaron en la cerámica estilo Carambolo y sintieron como propia, un sentimiento de apropiación que queda patente en la plasmación de esta decoración sobre formas locales. Posteriormente, durante la Primera Edad del Hierro y como consecuencia de una presencia fenicia estable en la península ibérica, se desarrolló en el suroeste un artesanado tartésico con una decoración orientalizante que podría explicar la progresiva desaparición de la cerámica estilo Carambolo, al no entrar en coherencia con los nuevos gustos estilísticos y las nuevas formas de representación.

\section{Agradecimientos}

Este trabajo se ha podido realizar gracias a la concesión de un contrato de orientación postdoctoral del plan propio de la Universidad de Castilla-La Mancha. Mis agradecimientos se extienden al doctor Mariano Torres Ortiz, por permitirme el acceso al estudio de las piezas de Cerro Macareno, y al equipo de investigación que trabaja en el oppidum de Alarcos, dirigido por la doctora Rosario García Huerta por haber costeado las analíticas a través del proyecto: «Investigaciones arqueológicas en la necrópolis ibérica y en el oppidum de Alarcos, sector III (Ciudad Real)», concedido por la Consejería de Educación, Cultura y Deportes de la Junta de Comunidades de Castilla-La Mancha.También agradezco al doctor Antonio Pizzo su colaboración y por haberme permitido el acceso a unos recursos bibliográficos fundamentales para la realización de este trabajo en la Escuela Española de Historia y Arqueología en Roma (EEHAR-CSIC). 
Bibliografía

Abad, L. (1979): "Consideraciones en torno a Tartessos y el origen de la cultura ibérica”. Archivo Español de Arqueología, 52: 175-194.

Almagro-Gorbea, M. (1977): El Bronce Final y el Periodo Orientalizante en Extremadura. Bibliotheca Praehistorica Hispana, I4. Real Academia de la Historia. Madrid.

Almagro-Gorbea, M. (1986): "Bronce Final y Edad del Hierro. La formación de las etnias y culturas prerromanas". En F. Jordá, M. Pellicer, P. Acosta y M. Almagro-Gorbea (eds.): Historia de España. Prehistoria. Gredos. Madrid: 34I-532.

Alvar, J. (2008): "Modos de contacto y medios de comunicación: los orígenes de la expansión fenicia”. En S. Celestino, N. Rafel y X-L Armada Pita (eds.): Contacto cultural entre el Mediterráneo y el Atlántico (siglos XII-VIII ane). La precolonización a debate. CSIC. Madrid: I7-26.

Amores, F. de (1995): "La cerámica pintada estilo Carambolo: una revisión necesaria de su cronología”. En Tartessos 25 años después 1968-1993. Actas del Congreso Conmemorativo del $V$ Symposium Internacional de Prehistoria Peninsular (Cádiz, 1993). Ayuntamiento de Jerez de la Frontera. Cádiz: 159-178.

Aubet, M.E. (I982): “Un vaso a mano con decoración pintada de Los Alcores de Carmona”. Trabajos de Prehistoria, 39: 385-388.

Aubet, M.E., Serna, M.R., Escacena J.L. y Ruiz Delgado, M.M. (1983): La Mesa de Setefilla. Lora del Río (Sevilla). Campaña de 1979. Excavaciones Arqueológicas en España I22. Ministerio de Cultura. Madrid.

Barrios, J., Montealegre, L. y López Palomo, L.A. (2010): "Caracterización mineralógica y textual de cerámicas tartésicas de Ategua (Córdoba, España)". Boletín de la Sociedad Española de Cerámica y Vidrio, 49.5:36I-370.

Barros, P. (20I2): "O Bronze Final na região de Mértola”. En J. Jiménez Ávila (ed.): Siderum Ana II. El rio Guadiana en el Bronce Final. Anejos de Archivo Español de Arqueología 62. IAM-CSIC. Mérida: 215-227.
Belén, M. (200I): "La cremación en las necrópolis tartésicas”. En M.R. García Huerta y F.J. Morales (coords.): Arqueología funeraria. Las necrópolis de incineración. Universidad de CastillaLa Mancha. Madrid: $37^{-78}$.

Belén, M. y Escacena, J.L. (1997): “Testimonios religiosos de la presencia fenicia en Andalucía occidental". SPAL, 6: I03-гзг.

Belén, M. y Escacena, J.L. (2002): "La imagen de la divinidad en el mundo tartésico". En E. Ferrer (ed.): Ex Oriente Lux: las religiones orientales antiguas en la península ibérica. SPAL monografías 2. Universidad de Sevilla. Sevilla: 159-I83.

Bendala, M. (1979): "Las más antiguas navegaciones griegas a España y el origen de Tartessos". Archivo Español de Arqueología, 52: 33-38.

Blasco, M.C. (I980-I98I): "Reflexiones sobre la cerámica pintada del Bronce Final y Primera Edad del Hierro en la Península Ibérica”. Cuadernos de Prehistoria y Arqueología de la Universidad Autónoma de Madrid, 7-8: 75-92.

Brandherm, D. (2008): "Vasos a debate. La cronología del Geométrico griego y las primeras colonizaciones en Occidente". En S. Celestino, N. Rafel y X-L Armada Pita (eds.): Contacto cultural entre el Mediterráneo y el Atlántico (siglos XII-VIII ane). La precolonización a debate. CSIC. Madrid: 93-Io6.

Brandherm, D. y Krueger, M. (20I7): "Primeras determinaciones radiocarbónicas de la necrópolis de Setefilla (Lora del Río) y el inicio del periodo orientalizante en Andalucía occidental". Trabajos de Prehistoria, 74(2): 296-318.

Buero, M.S. (1984): "Los motivos naturalistas en la cerámica pintada del Bronce Final del suroeste peninsular". Habis, 15: 345-364.

Buero, M.S. (1987): "El Bronce Final y las cerámicas «tipo Carambolo»". Revista de Arqueología, 8.70: 35-47.

Buero, M.S. y Fernández Gómez, F. (2010): "La cerámica tipo Carambolo en la Universidad Laboral de Sevilla: problemática del Bronce y del Orientalizante en Andalucía Occidental". Temas de Estética y Arte, 24: 39-68.

Cabrera, P. (198I): "La cerámica pintada de Huelva”. Huelva Arqueológica, 5: 317-335. 
Cáceres, Y.E.(1997): “Cerámicas y tejidos: sobre el significado de la decoración geométrica del Bronce Final en la Península Ibérica”. Complutum, 8: 125-I40.

Carriazo, J. de M. (1969): "El Cerro del Carambolo". En Tartessos y sus problemas. V Symposium Internacional de Prehistoria Peninsular (Jerez de la Frontera, I968). Universidad de Barcelona. Barcelona:3II-340.

Carriazo, J. de M. (1973): Tartesos y El Carambolo. Ministerio de Educación y Ciencia. Madrid.

Casado, M. (2003): "Reflexiones sobre la cerámica tipo Carambolo. ¿Un posible axioma de la arqueología protohistórica del suroeste andaluz?". SPAL, I2: 283-298.

Casado, M. (2015): La cerámica con decoración geométrica del Carambolo. SPAL monografías, 2I. Universidad de Sevilla. Sevilla.

Casado, M. (2019): "La cerámica tipo Carambolo: materialidad y desmaterialización de un hito historiográfico". En E. Rodríguez González y S. Celestino (eds.): Las cerámicas a mano pintadas postcocción de la peninsula ibérica durante la transición entre el Bronce Final y la IEdad del Hierro. MYTRA, Monografias y Trabajos de Arqueología, 4.IAM-CSIC.Mérida: 9-38.

Castro, P. V., Lull, V. y Micó, R. (1996): Cronología de la Prehistoria Reciente de la peninsula ibérica y Baleares (c. 2800-900 cal ANE). British Archaeological Reports International Series, 652. Archaeopress. Oxford.

Celestino, S. (200I): Estelas de guerrero y estelas diademadas. La precolonización y la formación del mundo tartésico. Bellaterra. Barcelona.

Celestino, S., Rodríguez González, E. y Donate, I. (2018): "Las cerámicas pintadas con bicromía poscocción de la vertiente atlántica ibérica". Zephyrus, 82.2: II9-I48.

Celestino, S. y López-Ruiz C. (2020): Tarteso y los fenicios de Occidente. Almuzara. Córdoba.

Coldstream, J.N. (1968): Greek Geometric Pottery. A survey of ten local styles and their chronology. Methuen. London.

Delgado, A. (20ro): "Encuentros en la liminalidad: espacios sagrados, contactos e intercambios en el sur de Iberia en los inicios del I milenio a.C.”. En M. Dalla Riva y H. di Giuseppe (eds.): Mettings between Cultures in the Ancient Mediterranean. Proceedings of the $I^{\text {th }}$ International Congress of Classical Archaeology. Rome 22-26 september 2008. Bollettino di archeologia online, volume speciale: I-I4.
Esteve, M. (1945): Excavaciones de Asta Regia (Mesas de Asta, Jerez). Campaña de 1942-43. Acta Arqueológica Hispánica 3. Ministerio de Educación Nacional, Comisaría General de Excavaciones Arqueológicas. Madrid.

Fernández Flores, A.y Rodríguez Azogue, A. (2007): Tartessos desvelado. La colonización fenicia del suroeste peninsular y el origen y ocaso de Tartessos. Almuzara. Córdoba.

Fernández Gómez, F. y Buero, M.S. (2010): “E1 problema del origen y cronología del Bronce Final-Orientalizante en Andalucía Occidental a través del fondo de cabaña de la Universidad Laboral de Sevilla”. Temas de Estética y Arte, 24: 69-IIо.

Fernández Miranda, M.(1979): "Horizonte cultural tartéssico y hallazgos griegos en el sur de la Península". Arcbivo Español de Arqueología, 52: 49-66.

Fernández Jurado, J. (1988-1989): Tartessos y Huelva. Huelva Arqueológica io-Ir. Huelva.

Galván, V. (1986): "Análisis de pastas cerámicas". El yacimiento metalúrgico de época tartésica de San Bartolomé de Almonte (Huelva), Huelva Arqueológica 8 (I): 275-33I.

García Alfonso, E. (2016): "Las primeras importaciones griegas en Occidente y la cronología de la cerámica geométrica: hacia un nuevo paradigma (I)". Menga. Revista de Prehistoria de Andalucia, 7 : IоI-I32.

García Alfonso, E. (2017): "Las primeras importaciones griegas en Occidente y la cronología de la cerámica geométrica: hacia un nuevo paradigma (II)". Menga. Revista de Prehistoria de Andaluciá, 8: I43-I78.

García Fernández, F.J. (2020): "Cerro Macareno (La Rinconada, Sevilla): nuevos datos sobre su secuencia de ocupación y rasgos constructivos". SPAL, 29.I: 93-I27.

García Huerta, M.R. (20I9): "Las cerámicas postcocción de la Meseta Sur: el ejemplo de Alarcos (Ciudad Real)", En E. Rodríguez González y S. Celestino (eds.): Las cerámicas a mano pintadas postcocción de la península ibérica durante la transición entre el Bronce Final y la I Edad del Hierro. MYTRA, Monografías y Trabajos de Arqueología, 4. IAM-CSIC. Mérida: 39-74. 
García Huerta, M.R. y Fernández Rodríguez, M. (2000): "La génesis del mundo ibérico en la submeseta sur: el tránsito del Bronce Final-I Edad del Hierro en Alarcos". Cuadernos de Prehistoria y Arqueología de la Universidad Autónoma de Madrid, 26: 47-68.

González de Canales, F., Serrano Pichardo, L. y Llompart, J. (2004): El emporio fenicio precolonial de Huelva (ca. 9oo-77o a.C.). Biblioteca Nueva. Madrid.

González de Canales, F., Serrano Pichardo, L. y Llompart, J. (20I0): "El inicio de la Edad del Hierro en el suroeste de la Península Ibérica, las navegaciones precoloniales y cuestiones en torno a las cerámicas de Huelva”. En J.A. Pérez Macías y E. Romero (coords.): IV Encuentro de Arqueologia del Suroeste Peninsular. Universidad de Huelva. Huelva: 648-697.

González de Canales, F., Serrano Pichardo, L., Llompart, J., García Fernández, M., Ramon, J., Domínguez Monedero, A.J. y Montaño, A. (2017): "Archaeological finds in the deepest anthropogenic stratum at 3 Concepción street in the city of Huelva". Ancient West and East, I6: I-6I.

González Rodríguez, R., Aguilar Moya, L.y Barrionuevo, F.J. (1995): "Mesas de Asta, un centro indígena tartésico en los esteros del Guadalquivir". En Tartessos 25 años después 1968-1993. Actas del Congreso Conmemorativo del V Symposium Internacional de Prehistoria Peninsular (Cádiz, 1993). Ayuntamiento de Jerez de la Frontera. Cádiz: $215-237$.

Guirao, D. (2014): Caracterización arqueométrica de las cerámicas ibéricas de los yacimientos de Alarcos y el Cerro de las Cabezas. Tesis doctoral. Universidad de Castilla-La Mancha. Ciudad Real.

Hunt M.A. y García Rivero, D. (20I7): "El asentamiento protohistórico de Jardín de Alá (Salteras, Sevilla)". En S. Celestino y E. Rodríguez González (eds.): Territorios comparados: los valles del Guadalquivir, el Tajo y el Guadiana en época tartésica. Reunión cientifica, Mérida (Badajoz, España) 3-4 diciembre 20I5. Anejos de Archivo Español de Arqueología, 8o. IAM-CSIC. Mérida: 47-77.
López Castro, J.L., Ferjaoui, A., Mederos, A., Martínez Hahnmüler, V. y Ben Jerbania, I. (2016): "La colonización fenicia inicial en el Mediterráneo Central: nuevas excavaciones arqueológicas en Útica (Túnez)”. Trabajos de Prehistoria, 73.r: 68-89.

Maluquer de Motes,J.(1960): "Nuevas orientaciones en el problema de Tartessos". En I Symposium de Prehistoria peninsular (Pamplona, 1959). Pamplona: 273-30I.

Mederos, A. (2017): "La cronología de la cerámica pintada monocroma roja tipo Carambolo del Bronce Final IIC-III e inicios de la Edad del Hierro del suroeste de la Península Ibérica (II50-825 a.C.)". En D. Brandherm (ed.): $M e-$ mento dierum antiquorum... Festschrift für $M a-$ jolie Lenerz-de Wilde zum 7o. Geburstag. Archaeologia Atlantica Monographiae, r. Curach Bhan. Hagen-Westfalia: I05-125.

Pellicer, M. (1969): “Las primeras cerámicas a torno pintadas andaluzas y sus problemas”. En Tartessos $y$ sus problemas. $V$ Symposium Internacional de Prehistoria Peninsular (Jerez de la Frontera, 1968). Universidad de Barcelona. Barcelona: 29I-3IO.

Pellicer, M. (1979-80): "Ensayo de periodización y cronología tartésica y turdetana". Habis, Io-Ir: 307-333.

Pellicer,M. (2006): "Momentos precoloniales y precolonización en Iberia”. Rivista di Studi Fenici, 34.r: 9-36.

Pellicer, M., Escacena, J.L. y Bendala, M. (1983): El Cerro Macareno. Excavaciones Arqueológicas en España, I24. Ministerio de Cultura. Madrid.

Pérez-Jordá, G., Peña-Chocano, L., García Fernández, M. y Vera Rodríguez, J.C. (2017): “The beginnings of fruit tree cultivation in the Iberian Peninsula: plant remains from the city of Huelva (Southern Spain)". Vegetation History and Archaeobotany, 26: 527-538.

Polvorinos del Río, A.J. (2010): "Análisis arqueométrico de cerámicas del asentamiento de El Trastejón (Huelva) y Sierra Morena Occidental”. En V.M. Hurtado, L. García Sanjuán y M.A. Hunt (coords.): El asentamiento de El Trastejón (Huelva). Investigación en el marco de los procesos sociales y culturales de la Edad del Bronce en el suroeste de la peninsula ibérica. Junta de Andalucía. Sevilla: 262-279. 
Renfrew, C. y Bahn, P. (2008): Arqueología. Conceptos clave. Akal. Madrid ( $\mathrm{I}^{\mathrm{a}}$ ed. 2005).

Ruiz Gálvez, M.L. (1993): "El occidente de la Península Ibérica. Punto de encuentro entre el Mediterráneo y el Atlántico a fines de la Edad del Bronce". Complutum, 4: 4I-68.

Ruiz Mata, D. (1984-1985): "Puntualizaciones sobre la cerámica pintada tartésica del Bronce FinalEstilo carambolo o Guadalquivir I". Cuadernos de Prehistoria y Arqueología de la Universidad Autónoma de Madrid, II-I2: 225-243.

Ruiz Mata, D. (1995): "Las cerámicas del Bronce Final. Un soporte tipológico para delimitar el tiempo y el espacio tartésico". En Tartessos 25 años después 1968-1993. Actas del Congreso Conmemorativo del $V$ Symposium Internacional de Prehistoria Peninsular (Cádiz, 1993). Ayuntamiento de Jerez de la Frontera. Cádiz: 265-313.

Sánchez, A., Tuñón,J.A., Parras, D.J., Montejo, M., Lechuga, M.A., Ceprián, B., Soto, M. y Luque, A. (2019): "MRS, EDXRF and GC-MS analysis for research on the ritual and funerary areas of Cerro de los Vientos (Baeza, Jaen, Spain). Native and Eastern Mediterranean influences". Journal of Archaeological Science: Reports, 28: I-I4.

Schattner, T.G. (2000): "Formas de Grecia oriental en la cerámica «tartésica»". Habis, 31: 63-72.

Schubart, H. (1971): "Acerca de la cerámica del Bronce Tardío en el sur y oeste peninsular." Trabajos de Prehistoria, 28: 151-182.

Torres, M. (2002): Tartessos. Bibliotheca Archaeologica Hispana, I4. Studia Hispano-phoenicia, I. Real Academia de la Historia. Madrid.
Torres, M. (2008): "The Chronology of the Late Bronze Age in Western Iberia and the beginning of the Phoenician colonization in the Western Mediterranean". A new Dawn for the Dark Age? Shifting Paradigms in Mediterranean Iron Age Chronology. British Archaeological Reports International Series, i87r. Archaeopress. Oxford: I35-I47.

Torres, M. (2016): "Algunas consideraciones cronológicas sobre el yacimiento tartésico de E1 Carambolo". Cadernos do Museu da Lucerna, II. Atas da Mesa Redonda Turdetânea e turdetanos. Castro Verde: 78-96.

Torres, M. (2019): "Síntesis y conclusiones". En E. Rodríguez González y S. Celestino (eds.): Las cerámicas a mano pintadas postcocción de la peninsula ibérica durante la transición entre el Bronce Final y la I Edad del Hierro. MYTRA, Monografías y Trabajos de Arqueología, 4. IAM-CSIC. Mérida: $237^{-244}$.

Urbina, D. y Morín, J. (2017): “La Primera Edad del Hierro en la submeseta sur". En Colonos en los inicios de la Edad del Hierro en Madrid. Las longhouses de Las Camas en Villaverde Bajo. Comunidad de Madrid. Madrid: 22-25.

Vilaça, R., Soares, I., Osório, M. y Gil, F. (20I8): "Cerâmicas pintadas de 'tipo Carambolo' na Beira Interior (Centro de Portugal)”, SPAL, 27 (2): 55-88.

Werner, S.E. (1990): La cerámica pintada geométrica del Bronce Final y de la Primera Edad del Hierro. La Muralla. Madrid. 